See Article page 1452.

\section{Commentary: Do not "futz" with Laplace}

\author{
John A. Elefteriades, MD, PhD (hon), ${ }^{\text {a }}$ Wei Sun, $\mathrm{PhD},{ }^{\mathrm{b}}$
} and Bulat A. Ziganshin, $\mathrm{MD}, \mathrm{PhD}^{\mathrm{a}}$

Video clip is available online.

Wang and colleagues ${ }^{1}$ are to be congratulated for their excellent article on wall stress analysis in ascending thoracic aortic aneurysms (TAAs), ${ }^{1}$ which presents a valuable and promising contribution to understanding the biomechanics of TAA disease. The main findings of this article are that (1) diameter and wall stress correlate well for larger TAAs and (2) small TAAs manifest a higher variation in peak stress relative to diameter. Imperfect correlation of wall stress with a single aortic diameter is not surprising, given the complex shape of the ascending aorta - not the uniform cylinder to which Laplace's law would directly apply.

It is universally accepted that biomechanical factors play a fundamental role in the natural history of aneurysms and dissections. $^{2-6}$ On the basis of engineering principles of material failure, aneurysm rupture and dissection should occur when the aortic wall stress exceeds the failure strength criteria of the vessel wall., ${ }^{5,7-9}$ Video 1 shows biaxial mechanical testing of human aortic tissue.

To accurately assess the rupture/dissection risk of an individual patient from the engineering perspective, one needs to obtain 4 key pieces of information from the patient: 3-dimensional aortic aneurysm geometry, elastic material

\footnotetext{
From the a Aortic Institute at Yale New-Haven, Yale University School of Medicine, New Haven, Conn; and ${ }^{b}$ Department of Biomedical Engineering, Georgia Institute of Technology and Emory University, Atlanta, Ga.

Disclosures: Dr Elefteriades: Principal, CoolSpine; Consultant for CryoLife; Data/Safety Monitoring Board for Terumo. Dr Sun: Co-founder and Chief Scientific Advisor, Dura Biotech. Dr Ziganshin has nothing to disclose with regard to commercial support.

Received for publication March 2, 2020; accepted for publication March 4, 2020; available ahead of print March 19, 2020.

Address for reprints: John A. Elefteriades, MD, PhD (hon), Aortic Institute at YaleNew Haven, Yale University School of Medicine, 789 Howard Ave, Clinic Building CB 317, New Haven, CT 06519 (E-mail: john.elefteriades@yale.edu).

J Thorac Cardiovasc Surg 2021;162:1463-6

$0022-5223 / \$ 36.00$

Copyright (c) 2020 by The American Association for Thoracic Surgery

https://doi.org/10.1016/j.jtcvs.2020.03.008
}

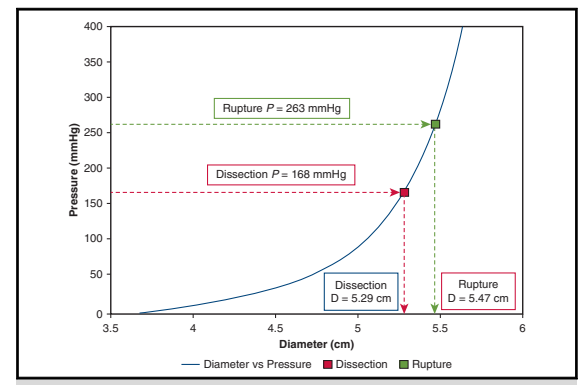

Precisely measured wall strength predicts aortic events at clinically relevant dimensions. Modified and reproduced with permission from Elefteriades JA, Habel N, Sun W, Sang AX, Kuzmik GA. The aortic wall: four questions and insights. $J$ Thorac Cardiovasc Surg. 2013;145:S130-4.

\section{CENTRAL MESSAGE}

Despite intricate finite element analysis of wall tension, prediction of rupture or dissection requires knowledge of the failure strength of the aortic wall.

properties, loading/boundary conditions, and tissue failure strength (eg, ultimate tensile strength).

The peak aortic wall stress can be calculated using the finite element methods, as the authors have done. If the calculated peak aortic wall stress exceeds the tissue failure strength, then rupture or dissection should occur. Peak wall stress by itself cannot determine whether the aneurysm tissue will rupture or not: It must be compared with the tissue failure strength. The authors have not calculated or incorporated tissue failure strength.

The current size-based guidelines, using $5.0-$ to $5.5-\mathrm{cm}$ aortic diameter as an elective surgery criterion, were derived from extensive large patient population studies. ${ }^{10}$ Furthermore, prior engineering studies, taking into account patient-specific tissue elastic properties and tissue failure strength, ${ }^{11}$ and patient-specific 3-dimensional geometries and loading/boundary condition, ${ }^{12-15}$ also support the conclusion that patients with aneurysm and an aortic diameter greater than $5 \mathrm{~cm}$ have a high rupture risk (Figure 1).

Beyond the engineering aspects, we would like to explore several clinical points related to this article.

\section{Aortic size paradox}

The authors emphasize repeatedly that (based on Pape and colleagues' International Registry of Acute Aortic Dissection study ${ }^{16}$ ) many aortic dissections occur below the usual anatomic size thresholds for surgical intervention. 


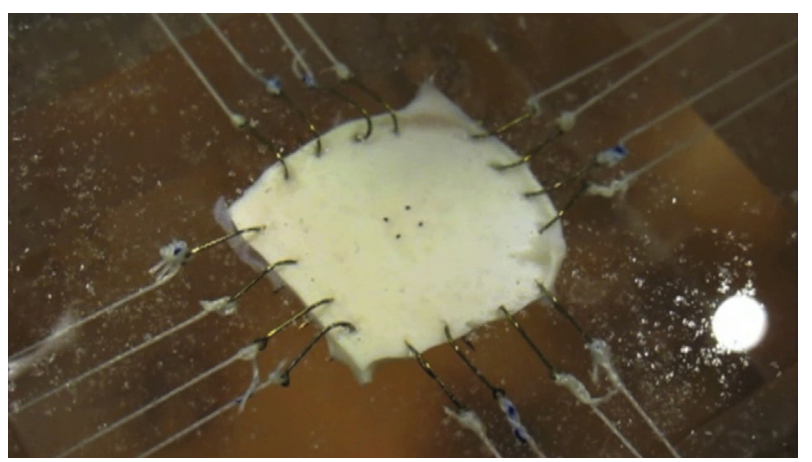

VIDEO 1. Biaxial stretching of human aortic aneurysm specimen, for precise calculation of mechanical properties. (From Dr Wei Sun, on specimens from the Aortic Institute at Yale New Haven.) Reprinted with permission from Elefteriades JA, Habel N, Sun W, Sang AX, Kuzmik GA. The aortic wall: four questions and insights. $J$ Thorac Cardiovasc Surg. 2013;145:S130-134. Video available at: https://www.jtcvs.org/article/ S0022-5223(20)30586-9/fulltext.

We have published on this topic previously, via detailed analysis of population dynamics. Simply put, in the bell curve of aortic size, patients with large aortas are very few (tip of the "tail" of the bell curve), whereas smaller aneurysms are more common. So, the percent rate of dissection (compared with the number at risk at each dimension) remains higher for the patients with larger aneurysms (6000-fold higher) ${ }^{17}$ (Figure 2). So, size still matters quite a bit and predicts quite well, when population dynamics are considered. Further, we have recently recommended a "left-shift" to a lower aortic diameter for surgical intervention, ${ }^{18}$ to $5 \mathrm{~cm}$, which would pick up most of the patients who were reported in the International Registry of Acute Aortic Dissection study. Furthermore, correction for patient size, via our "aortic size-body height" nomogram, would pick up even more such patients. ${ }^{19}$ Even further, our "real-world" study of the size-based predictive algorithm for intervention found it to be effective, with few aortic events in the patients anatomically triaged to medical treatment (no surgery). ${ }^{20}$

\section{Limitation of analysis}

Wall thickness was assumed to be uniform at $1.75 \mathrm{~mm}$. For simplicity, the authors set their wall thickness at a presumed $1.75 \mathrm{~mm}$. This presumption severely weakens their analysis. The human diseased aorta is not of uniform thickness. Laplace's law takes this into account, but not the authors' analysis (Figure 3 and Video 2).

3. Natural history studies speak for themselves, without engineering requirements.

The authors imply that because our natural history studies $^{10,19,21-24}$ use diameter as a criterion for outcome, they depend on Laplace's law. However, outcomes are outcomes. None of the natural history calculations directly involve Laplace's law or any other engineering calculations. A given diameter leads to certain observed outcomes (dissection, rupture, death). Mechanical

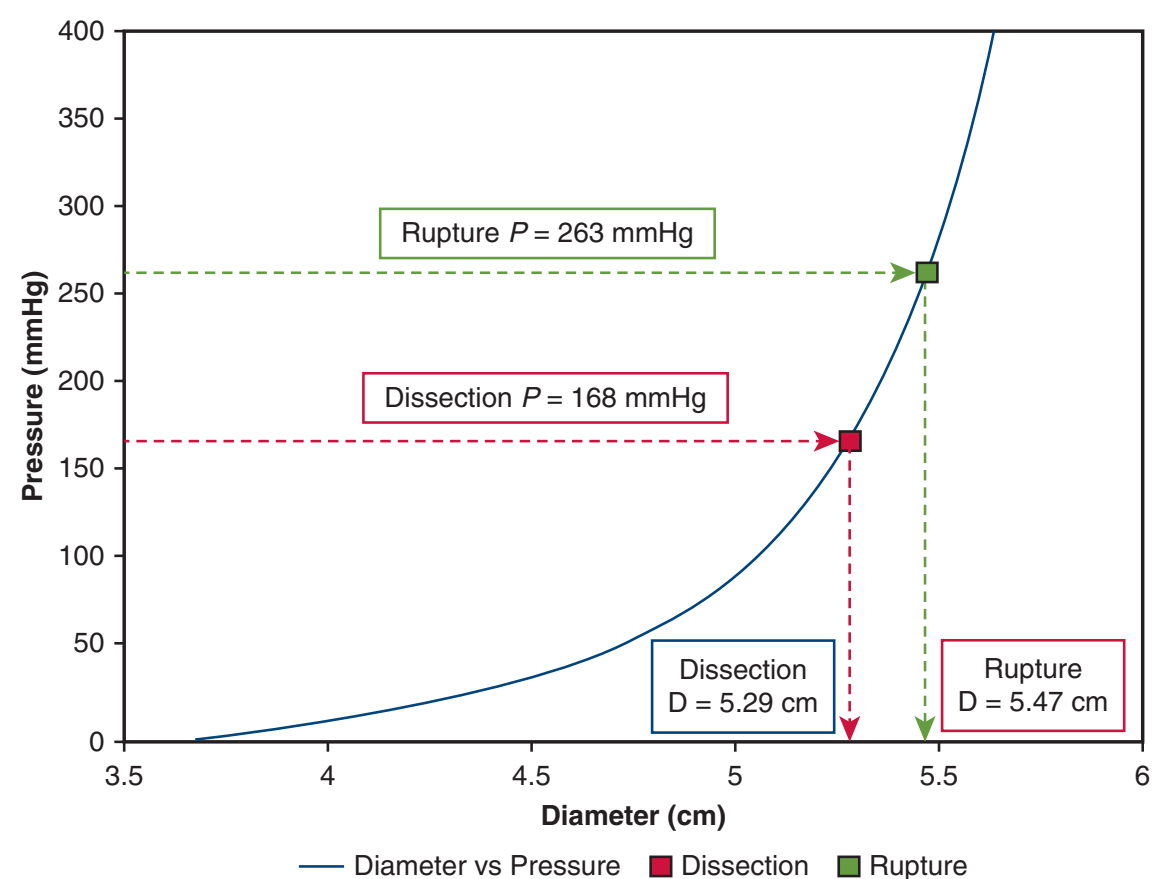

FIGURE 1. Example of results of biaxial stretch testing of single human aortic aneurysm specimen. Note that dissection is predicted to occur at a diameter between 5 and $5.5 \mathrm{~cm}$ and a pressure of $165 \mathrm{~mm} \mathrm{Hg}$. Rupture of the tissue is predicted at somewhat higher pressures and diameters. Modified with permission from Elefteriades JA, Habel N, Sun W, Sang AX, Kuzmik GA. The aortic wall: four questions and insights. J Thorac Cardiovasc Surg. 2013;145:S130-4. 


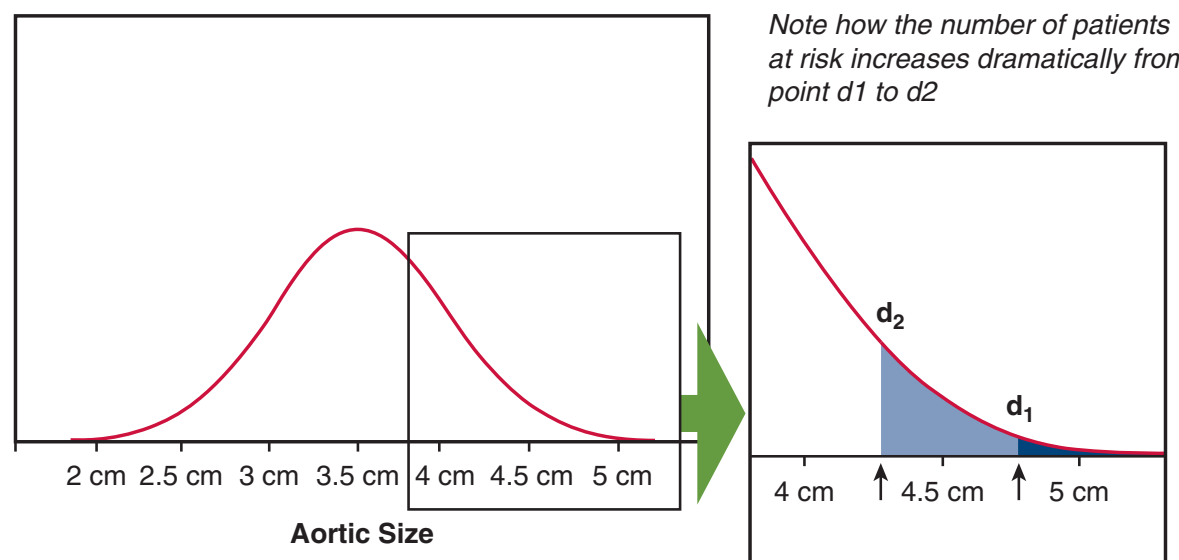

FIGURE 2. Hypothesized role of bell curve characteristics in mitigating observation of some aortic dissections occurring at small aortic size. Note how small the "tails" of such a curve are. Large aneurysms would reside far out in the tails. Although dissections do occur at small dimensions, note how rapidly the at-risk group increases in number as the putative criterion diameter goes from $d_{1}$ to $d_{2}$. We anticipate that millions of Americans harbor small TAAs, making for a very large denominator of vulnerable patients and a correspondingly low likelihood of dissection at small sizes. Modified with permission from Elefteriades JA, Farkas EA. Thoracic aortic aneurysm: clinically pertinent controversies and uncertainties. J Am Coll Cardiol. 2010;55:841-57.

properties of the aorta certainly play a role in these outcomes, but the outcomes are what they are, even without an engineering explanation.

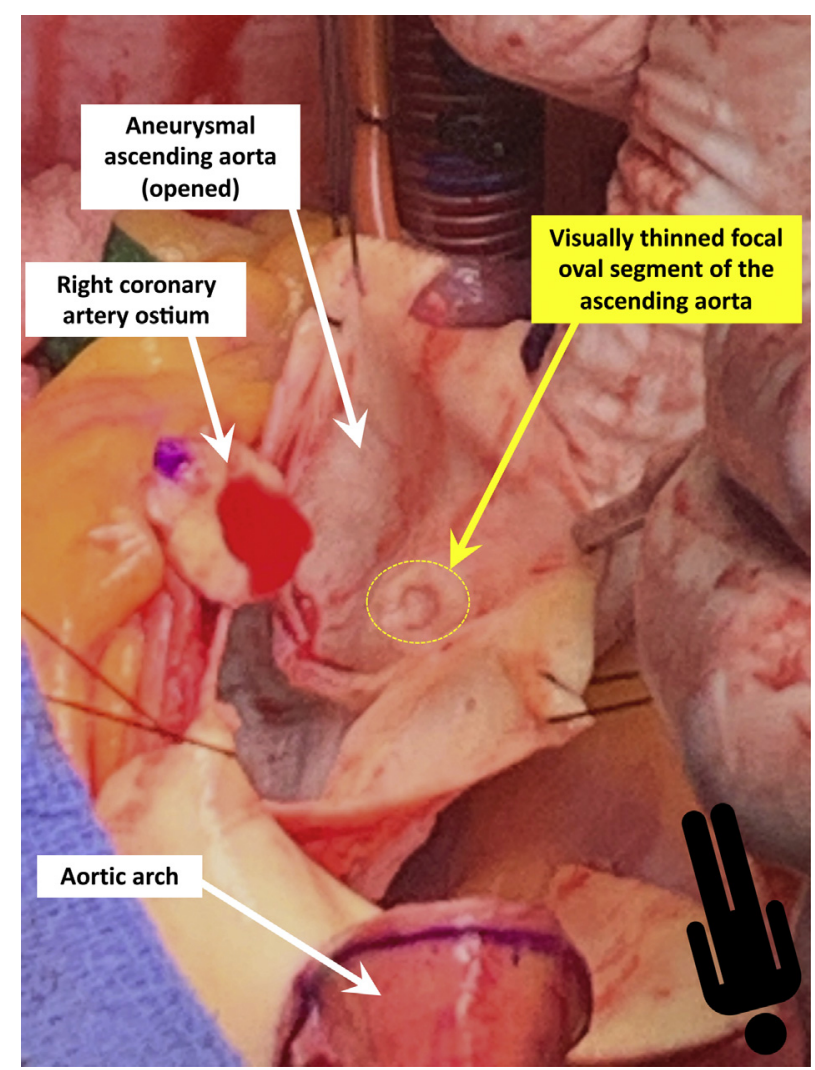

FIGURE 3. Please note the very thinned out oval segment in the right anterolateral portion of the ascending aorta in a patient with Marfan syndrome (yellow arrow and yellow circle). Such thinning will raise local wall tension substantially. See also Video 2.
4. Diameter is essential in decision-making, but we agree strongly with the authors that other factors must be taken into account as well.

The authors point out that our group has concentrated on diameter as a predictor of adverse aortic events and as a criterion for surgical intervention. Indeed, we have done so. ${ }^{10,19,21-}$ ${ }^{24}$ However, we, like the authors, have always emphasized that other factors come into play and must be considered for optimal decision making. Specifically, the following:

- Symptoms are important. A patient with a painful aneurysm requires resection regardless of size. ${ }^{25}$

- Patient size is important in putting a specific aortic diameter into perspective. That is why we now use a height nomogram, especially for very small or very large patients. ${ }^{19}$

- Genetic predisposition is important. That is why we recommend whole exome sequencing for all patients

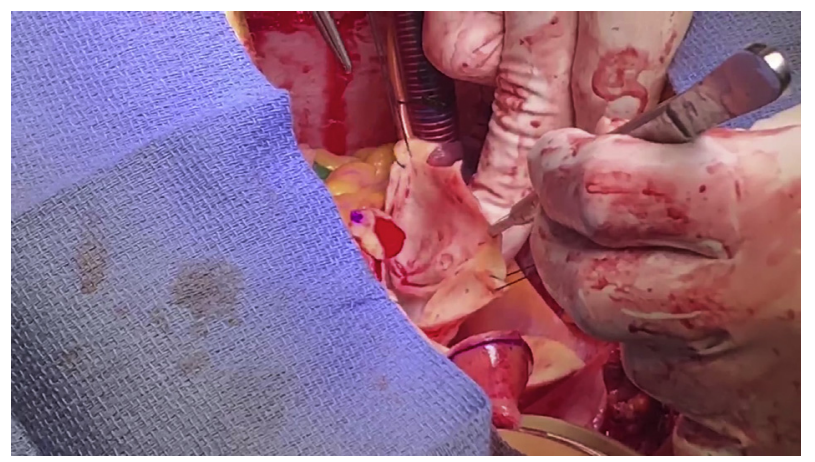

VIDEO 2. Video recorded during ascending aortic replacement in a patient with Marfan syndrome. Please note the very thinned out oval segment in the right anterolateral portion of the ascending aorta (see also Figure 2). Video available at: https://www.jtcvs.org/article/S0022-5223(20)30586-9/ fulltext. 
with ascending aortic aneurysm. ${ }^{26}$ Many specific mutations behave in a more malignant fashion and require earlier surgical intervention than size alone would suggest. ${ }^{27}$

- Family history is extremely important. Once there has been 1 dissection in the family, the risk of events in another family member is increased 3 -fold. ${ }^{28}$

5. We do not need to impugn Laplace just because his law is not the whole story in aneurysm disease.

A theme throughout the article by Wang and colleagues ${ }^{1}$ seems to be that Laplace has let us down in aneurysm disease. This is not fair. Laplace's law is a fundamental physical law of the material world. Laplace characteristics influence multiple body functions and organs, including blood pressure regulation, bladder function, peripheral edema, lifting mechanisms, heart failure, alveolar patency, esophageal varices, uterine contraction, ocular pressure, and, of course, aneurysms. ${ }^{29}$ The authors state Laplace's law as

$$
\boldsymbol{T}=\boldsymbol{P} \times \boldsymbol{d}
$$

where $\mathbf{T}$ is wall tension, $\mathbf{P}$ is luminal pressure, and $\mathbf{d}$ is diameter. However, this is an oversimplification. The authors neglect the more complete form of Laplace's law, which states

$$
\boldsymbol{T}=\frac{\boldsymbol{P} \times \boldsymbol{d}}{\boldsymbol{t}}
$$

where $\mathbf{t}$ is wall thickness. A thicker wall will feel less tension at a given pressure and diameter than a thinner wall. Aortic wall thickness varies from individual to individual and from location to location. Please note in Figure 3 the very thinned out oval segment in the right anterolateral portion of the ascending aorta of this patient with Marfan syndrome. That segment will feel a very high wall tension. We need to give Laplace information about thickness for him to work his magic.

And, of course, the mechanical characteristics of the aortic wall itself come into play. Is the collagen intrinsically weak? Have lamellar layers been destroyed? Each patient will have a specific ultimate tensile strength of his/her aortic wall at which it will rupture when the local Laplace tension exceeds that value.

So, Laplace still reigns.

\section{References}

1. Wang Z, Flores N, Lum M, Wisneski AD, Xuan Y, Inman J, et al. Wall stress analyses in $\geq 5 \mathrm{~cm}$ versus $<5 \mathrm{~cm}$ ascending thoracic aortic aneurysm patients. J Thorac Cardiovasc Surg. 2021;162:1452-9.

2. Sumner DS, Hokanson DE, Strandness DE Jr. Stress-strain characteristics and collagen-elastin content of abdominal aortic aneurysms. Surg Gynecol Obstet. 1970;130:459-66.

3. Dobrin PB. Pathophysiology and pathogenesis of aortic aneurysms. Current concepts. Surg Clin North Am. 1989;69:687-703.

4. Humphrey JD, Canham PB. Structure, mechanical properties, and mechanics of intracranial saccular aneurysms. J Elast. 2000;61:49-81.
5. Vorp DA. Biomechanics of abdominal aortic aneurysm. J Biomech. 2007;40: 1887-902.

6. Humphrey JD, Taylor CA. Intracranial and abdominal aortic aneurysms: similarities, differences, and need for a new class of computational models. Annu Rev Biomed Eng. 2008;10:221-46.

7. He CM, Roach MR. The composition and mechanical properties of abdominal aortic aneurysms. J Vasc Surg. 1994;20:6-13.

8. Raghavan ML, Vorp DA. Toward a biomechanical tool to evaluate rupture potential of abdominal aortic aneurysm: identification of a finite strain constitutive model and evaluation of its applicability. J Biomech. 2000;33:475-82.

9. Thubrikar MJ, Labrosse M, Robicsek F, Al-Soudi J, Fowler B. Mechanical properties of abdominal aortic aneurysm wall. J Med Eng Technol. 2001;25:133-42.

10. Coady MA, Rizzo JA, Hammond GL, Mandapati D, Darr U, Kopf GS, et al. What is the appropriate size criterion for resection of thoracic aortic aneurysms? J Thorac Cardiovasc Surg. 1997;113:476-91.

11. Martin C, Sun W, Pham T, Elefteriades J. Predictive biomechanical analysis of ascending aortic aneurysm rupture potential. Acta Biomater. 2013;9:9392-400.

12. Martin C, Sun W, Elefteriades J. Patient-specific finite element analysis of ascending aorta aneurysms. Am J Physiol Heart Circ Physiol. 2015;308: H1306-16.

13. Polzer S, Gasser TC, Vlachovsky R, Kubíček L, Lambert L, Man V, et al. Biomechanical indices are more sensitive than diameter in predicting rupture of asymptomatic abdominal aortic aneurysms. J Vasc Surg. 2020;71:617-26.e6.

14. Polzer S, Gasser TC. Biomechanical rupture risk assessment of abdominal aortic aneurysms based on a novel probabilistic rupture risk index. $J$ R Soc Interface. 2015; 12:20150852.

15. Joldes GR, Miller K, Wittek A, Forsythe RO, Newby DE, Doyle BJ. BioPARR: a software system for estimating the rupture potential index for abdominal aortic aneurysms. Sci Rep. 2017;7:4641.

16. Pape LA, Tsai TT, Isselbacher EM, Oh JK, O'gara PT, Evangelista A, et al. Aortic diameter $>$ or $=5.5 \mathrm{~cm}$ is not a good predictor of type A aortic dissection: observations from the International Registry of Acute Aortic Dissection (IRAD). Circulation. 2007;116:1120-7.

17. Paruchuri V, Salhab KF, Kuzmik G, Gubernikoff G, Fang H, Rizzo JA, et al. Aortic size distribution in the general population: explaining the size paradox in aortic dissection. Cardiology. 2015;131:265-72.

18. Ziganshin BA, Zafar MA, Elefteriades JA. Descending threshold for ascending aortic aneurysmectomy: is it time for a "left-shift" in guidelines? J Thorac Cardiovasc Surg. 2019; 157:37-42.

19. Zafar MA, Li Y, Rizzo JA, Charilaou P, Saeyeldin A, Velasquez CA, et al. Height alone, rather than body surface area, suffices for risk estimation in ascending aortic aneurysm. J Thorac Cardiovasc Surg. 2018;155:1938-50.

20. Saeyeldin A, Zafar MA, Li Y, Tanweer M, Abdelbaky M, Gryaznov A, et al. Decision-making algorithm for ascending aortic aneurysm: effectiveness in clinical application? J Thorac Cardiovasc Surg. 2019;157:1733-45.

21. Davies RR, Goldstein LJ, Coady MA, Tittle SL, Rizzo JA, Kopf GS, et al. Yearly rupture or dissection rates for thoracic aortic aneurysms: simple prediction based on size. Ann Thorac Surg. 2002;73:17-28.

22. Davies RR, Gallo A, Coady MA, Tellides G, Botta DM, Burke B, et al. Novel measurement of relative aortic size predicts rupture of thoracic aortic aneurysms. Ann Thorac Surg. 2006;81:169-77.

23. Elefteriades JA, Ziganshin BA, Rizzo JA, Fang H, Tranquilli M, Paruchuri V, et al. Indications and imaging for aortic surgery: size and other matters. J Thorac Cardiovasc Surg. 2015;149:S10-3.

24. Zafar MA, Chen JF, Wu J, Li Y, Papanikolaou D, Abdelbaky M, et al. Natural history of descending thoracic and thoracoabdominal aortic aneurysms. J Thorac Cardiovasc Surg. November 11, 2019 [Epub ahead of print].

25. Elefteriades JA, Tranquilli M, Darr U, Cardon J, Zhu BQ, Barrett P. Symptoms plus family history trump size in thoracic aortic aneurysm. Ann Thorac Surg. 2005;80:1098-100.

26. Ziganshin BA, Bailey AE, Coons C, Dykas D, Charilaou P, Tanriverdi LH, et al. Routine genetic testing for thoracic aortic aneurysm and dissection in a clinical setting. Ann Thorac Surg. 2015;100:1604-11.

27. Faggion Vinholo T, Brownstein AJ, Ziganshin BA, Zafar MA, Kuivaniemi H, Body SC, et al. Genes associated with thoracic aortic aneurysm and dissection: 2019 update and clinical implications. AORTA (Stamford). 2019;7:99-107.

28. Ma WG, Chou AS, Mok SCM, Ziganshin BA, Charilaou P, Zafar MA, et al. Positive family history of aortic dissection dramatically increases dissection risk in family members. Int J Cardiol. 2017;240:132-7.

29. Basford JR. The Law of Laplace and its relevance to contemporary medicine and rehabilitation. Arch Phys Med Rehabil. 2002;83:1165-70. 